\title{
The road to Hell is paved with good intentions: The developing law of rectification and mistake
}

Received: 5th May, 2006

\section{Carolyn Saunders}

is a pensions partner and head of the Pensions Group at law firm Taylor Wessing. She advises employers and trustees on all aspects of pensions law. In particular she has been involved in a number of high-profile pensions cases, including two of the leading cases on rectification. She is a full member of the Association of Pension Lawyers and a member of its Education and Seminars subcommittee. She is a regular conference speaker.

\begin{abstract}
This paper considers the law of rectification and mistake and the rule in Hastings-Bass in light of the recent Gallaher case. It is not intended and does not purport to be a thorough analysis of law in each of these areas. Rather, it is a look at some of the interesting points to emerge from Gallaher.
\end{abstract}

Keywords: rectification, common intention, mistake, Hastings-Bass

\section{Rectification}

\section{Nature and effect}

Rectification is an equitable remedy. It is available where a written instrument fails, because of mistake, to express the true agreement between its parties. By rectification, the court can amend the written instrument so as to make it accord with the true agreement.

Rectification cannot affect the agreement itself. What is rectified is not the agreement but the parties' written expression of their agreement; specifically, 'Courts of equity do not rectify contracts; they may and do rectify instruments purporting to have been made in pursuance of the terms of contract'. ${ }^{1}$

Following rectification, the written instrument will be read as if it had always existed in its rectified form. The aim is to place the parties as far as possible in the position in which they would have been had the mistake not been made.

\section{Conditions}

For a rectification claim to succeed, the following conditions must be satisfied.

Written instrument

There must be a written instrument to be rectified. The jurisdiction to rectify is general and encompasses a wide range of written instruments, including contracts, conveyancing documents, voluntary settlements, share transfers and marriage settlements as well as pension scheme documents. $^{2}$

\section{Absence of alternative remedy}

A court will not award rectification if the desired result can conveniently be achieved by other means. For example:

- the parties' evidence of intention may be enforceable as a collateral contract; ${ }^{3}$

- the parties may have rectified or be able to rectify the instrument voluntarily; ${ }^{4}$ 
- where the mistake is obvious on the face of the instrument, the court may be able to correct the instrument as a matter of construction without the aid of extrinsic evidence. ${ }^{5}$

Note that an action in negligence (for example, against professional advisers who drafted the written instrument) is not regarded as an alternative remedy for these purposes as it is established that negligence is no bar to rectification. ${ }^{6}$ However, where a negligence claim exists, rectification, if appropriate, should be pursued first in order to mitigate loss ${ }^{7}$ - at least if the facts of the case are such that the evidence needed to substantiate the negligence and rectification claims are essentially the same. Where this is not the position, then the decision in Pilkington $v$ Wood $^{8}$ suggests that the duty to mitigate loss does not go so far as to require a party to embark on a difficult piece of litigation.

In the context of pension scheme documents the usual alternative remedies available where a mistake has been made are the execution of a deed of amendment and/or the issue of a further booklet or announcement. However, these remedies cannot be used:

- where this would infringe the scheme power of amendment; or

- if accrued rights or entitlements (as per s. 67 of the Pensions Act 1995) would or might be prejudiced; or

- as against a member who has acted to his detriment in reliance on the mistake.

This means that rectification in this context is most likely to be sought where a mistake has placed scheme members in a better position than was intended.

\section{Agreement or converging intentions}

A claim for rectification needs to be based on a prior agreement between the parties or on evidence of common intention. It seems that the exact requirement will depend on the nature of the transaction between the parties. ${ }^{9}$

\section{Continuing common intention}

Evidence of agreement or converging intentions is not sufficient on its own. In addition, the parties must demonstrate that it was still their intention, at the time at which they executed the written instrument, to put into effect the terms of the prior agreement or to reflect their converging intentions, as appropriate. ${ }^{10}$ Otherwise, differences between the written instrument and the previously agreed terms or alleged intention may be due to a decision by the parties to depart from such terms or intention rather than to any mistake.

The intention of the parties at the time of execution of the written instrument is paramount. The fact that the parties may have had a different intention had they known or thought about something that they were not aware of at the time is irrelevant. So, for example, rectification will not be granted if the instrument intentionally contains a provision which has a different meaning in fact from that understood by the parties at the time of execution. ${ }^{11}$

Particular evidential difficulties may arise where the parties have relied on professional advisers who have apparently failed to advise them adequately of the consequences of their alleged common intention. In principle, the fact that the parties may not have fully understood what they were doing should not matter provided that there is clear evidence of their intention. In practice, the involvement of third parties may have the effect of undermining the evidence of intention. 
It is unclear from the decided cases whether the validity of the common intention is important. Suppose the common intention would, had it been carried into effect, have produced an illegal or invalid result - for example, an intention may be formed to amend a pension scheme in a manner that is contrary to s. 67 of the Pensions Act 1995 and/or inconsistent with restrictions on the scheme's power of amendment. Although there is no authority directly on this point, there is authority to the effect that the quality of the decision making is irrelevant and it is well established that negligence is no bar to rectification. ${ }^{12}$

\section{Mistake}

There must have been a mistake as a result of which the written instrument does not accord with the parties' intentions. Typically, this will be a mistake of fact, but rectification is also available where there is a mistake of law in the sense that, at the time of execution of the written instrument, the parties were mistaken as to the legal effect and consequences of the instrument's terms - in other words, where there is a common intention as to what the legal effect and consequences should be. ${ }^{13}$ Where there is no such mistake, however, and the written instrument does accurately reflect the parties' prior agreement, the passing of subsequent legislation which changes the effect of the written instrument in a manner not intended by the parties does not amount to grounds for rectification. ${ }^{14}$

The general rule is that the mistake must be common to both parties, although there are three instances in which a unilateral mistake may be sufficient to allow the court to rectify:

- Fraud: rectification can be granted where only one party is mistaken but the other party is fraudulent (whether actual, constructive or equitable fraud). For instance, a party may be mistaken as to the meaning and effect of the terms of a written instrument because of the other party's fraudulent failure to explain those terms. ${ }^{15}$

- Estoppel: rectification is available where only one party is mistaken as to the terms of a written instrument; the mistake works to the advantage of the other party and the other party was aware of the first party's mistake. For instance, the parties may execute a document which is believed by the first party to contain a particular term which the second party knows to be omitted. The omission favours the second party and the second party is aware of the first party's mistaken belief. ${ }^{16}$ In such circumstances, the second party is estopped from objecting to rectification. ${ }^{17}$

- Unilateral transaction: where the written instrument gives effect to a unilateral transaction, evidence of a unilateral mistake will be sufficient. So, a voluntary settlement can be rectified at the instance of the settlor. ${ }^{18}$ This is the case even where the trustees are party to the voluntary settlement, provided that the settlement does not involve an actual bargain between the settlor and the trustees. ${ }^{19}$

\section{Burden and standard of proof}

The burden of proof is on the party seeking rectification and there are various judicial statements on the extent of that burden. The position appears to be that the normal civil standard of balance of probability applies, but that the evidence of intention must be convincing in order to counteract the terms of the written instrument. Per Brightman LJ:

'It is not, I think, the standard of proof which is high, so differing from the normal civil standard, but the evidential requirement 
needed to counteract the inherent probability that the written instrument truly represents the parties' intention because it is a document signed by the parties. ${ }^{20}$

Mere confusion between the parties as to what has been agreed is not sufficient. ${ }^{21}$

\section{Defences}

Rectification is a discretionary remedy. As such, the court may still refuse to grant rectification even if all of the conditions described above are satisfied. So, for example, the court will not grant rectification where this would prejudice a bona fide purchaser for value without notice who takes an interest conferred by the written instrument. Rectification is also likely to be refused if the parties cannot be restored to the position which they occupied prior to the execution of the written instrument in question. ${ }^{22}$

\section{Pension scheme rectification}

There have been only four cases dealing specifically with the rectification of pension schemes, namely Lansing Linde, ${ }^{23}$ $A M P,{ }^{24}$ the Gallaher case, ${ }^{5}$ and most recently, Drake Insurance $v$ MacDonald. ${ }^{26}$ All have been decisions at first instance. Each of the first three cases has developed the law a little further in terms of the way in which the rectification conditions apply in the context of pension schemes.

The current state of the law is reflected in the Gallaher case which was followed in Drake Insurance $v$ MacDonald. It is instructive to examine the Gallaher case in greater detail.

\section{Gallaher Ltd v Gallaher Pensions Limited}

The facts

These proceedings concerned deeds of amendment that were executed in 1987 and 1989 in respect of three Gallaher pension schemes - the A, B and $M$ schemes. The power of amendment in the $\mathrm{A}$ and $\mathrm{B}$ schemes was exercisable by the trustee (Gallaher Pensions Limited) with the consent of the principal employer (Gallaher Ltd). The power of amendment in the $\mathrm{M}$ scheme was executed by the principal employer with the consent of the trustees.

Deeds executed in 1987 introduced into each of the schemes a rule providing for 'pensions in payment' to be increased every year for ten years by the lower of 2 per cent or the increase in the Retail Prices Index. Deeds executed subsequently in 1989 removed the ten-year limit.

Gallaher Ltd claimed that the intention was for this increase only to apply to pensions in payment in excess of the guaranteed minimum pension and that this was consistent with a policy (the GMP Policy) that had been agreed in late 1980. It was claimed that the rationale for the GMP Policy was the fact that the State provided increases on guaranteed minimum pensions in payment and it was therefore unnecessary and illogical for the Gallaher schemes to do the same.

The relevant legislation providing for the State to increase GMPs changed with effect from 6th April, 1988. Thereafter pension schemes were required to confer 3 per cent Limited Price Indexation increases on GMPs earned after 5th April, 1988.

Gallaher Limited sought a declaration that the 1987 deeds could be construed to exclude GMPs from the increases to pensions in payment. In the alternative Gallaher claimed rectification of the 1987 deeds and, in the further alternative, claimed that the 1987 deeds should be set aside either under the rule in $R e$ Hastings-Bass ${ }^{27}$ or for mistake under the rule in Gibbon $v$ Mitchell. ${ }^{28}$ 
There was a similar claim for the 1989 deeds to be set aside under these rules.

\section{The decision}

Gallaher Ltd failed in its construction claim as the words used in the 1987 deeds were perfectly clear and free from ambiguity. Therefore the subjective intention of the parties could not be used to construe the deeds.

The claim for rectification succeeded. In the circumstances, there was no need for the court to determine the position under the rule in Re Hastings-Bass or under the law of mistake, however, some interesting obiter comments were made on these issues.

\section{The law}

The interest of the Gallaher decision lies in the conclusions reached on the nature of the evidence needed to demonstrate the requisite intention and also in relation to the assessment of that evidence.

\section{Outward expression/objective manifestation of accord}

Earlier rectification cases had distinguished between an outward expression of the parties' intention and an outward expression of the parties' 'accord'. The latter requires the intention of each party to have been communicated to the other.

In Lansing Linde Rimer J had expressed the view, obiter, that an outward expression of accord was required. In that case, the relevant powers provided for amendments to be made by the company with the consent of the trustees.

In Gallaher, however, Etherton J confirmed that an outward expression of accord is not required where the pension scheme power of amendment is exercisable by the sponsoring employer with the consent of the trustees, or vice versa. This followed Collins J's earlier decision in $A M P$ to the effect that, while such an amendment power requires the trustees and employer's wishes to coincide, it does not require them to agree among themselves. Consequently, an agreement should not be a requirement of rectification in these cases. $^{29}$

The inference to be drawn from both AMP and Gallaher is that the position may well be different where the wording of the power of amendment does require a genuine bilateral agreement between the trustee and the employer.

In fact, Collins $\mathrm{J}$ in $A M P$ drew a very clear distinction between cases where the power is exercisable by one party with the other party's consent and cases where the power is joint, describing that ' $\mathrm{a}$ power exercisable with consent is not the same as a joint power'. ${ }^{30}$

Therefore, in circumstances of a joint power the possibility is that the party seeking rectification will need to demonstrate the existence of an accord between the employer and the trustees.

\section{Outward expression/objective manifestation of intent}

Prior to the decision in Gallaher, it was unclear whether it is necessary to demonstrate some outward expression of the parties' common intention.

In Lansing Linde, Rimer J had suggested obiter that an outward expression of accord was required and so did not need to consider the requirement for an outward expression of intention.

$A M P$ is ambiguous on the point. Collins $\mathrm{J}$ made the following conflicting statements:

'It may be that the need for objective manifestation in the case of a unilateral transaction is simply one element of the need for convincing proof of the mistake' 
'when one is considering the intentions of a collective body such as a group of trustees or a committee of a board it is their collective intention which is relevant, and it would be a very odd case (and certainly not this one) if that collective intention were not objectively manifested'

'If objective manifestation of their intentions is a separate requirement, then there can be no doubt that it is fulfilled in abundance ${ }^{, 31}$

In Gallaher, Etherton J's interpretation of these apparently conflicting statements was that Collins $\mathrm{J}$ had held that an outward expression of intention was not necessary. Consequently, as this was not manifestly wrong he was bound to follow what he believed to be Collins J's decision.

The consequence of this is that a rectification claim could, in theory, succeed solely on the basis of witness evidence without any separate documentary corroboration.

\section{Subsequent conduct as evidence of intention}

Pre-Gallaher it was unclear whether, under English law, the parties can use conduct after the execution of the relevant document(s) as evidence of intention at the time of executing the document. Cases in both New Zealand and Australia had previously accepted that such evidence could be used. The only English authority to deal with this point, Dormer $v$ Sherman, ${ }^{32}$ allowed subsequent conduct to be admitted in evidence but did not expressly deal with this point in the judgment.

Etherton J confirmed in Gallaher that such evidence can be used. He relied on the decision in Dormer and on one Irish ${ }^{33}$ and two Antipodean authorities. ${ }^{34}$ Interestingly, he rejected the argument that changes after the execution of the 1987 deeds, in the trustee body and on the employer's board of directors, meant that the subsequent conduct should not be accepted as evidence of intention:

'irrespective of when precisely the composition of the boards of directors of GL and GPL changed, all those documents and matter evidence a continuing policy of GL and GPL of limiting increases ... to the part of the pension in excess of the GMP'. ${ }^{35}$

It goes without saying that the court should treat any evidence of subsequent conduct with caution as it may only show the parties' intentions at a date after the document was executed.

\section{The approach to the evidence}

There are many similarities between the facts surrounding the Lansing Linde case and the relevant facts in the Gallaher case. It is interesting to consider the very different ways in which Rimer $\mathrm{J}$ and Etherton $\mathrm{J}$ respectively approached the witness evidence before them in two particular respects: first, in relation to the effect of passage of time on the weight to be given to the witness evidence, and secondly in relation to the depth of understanding that the parties were expected to have of the intended amendments.

\section{The effect of passage of time}

In Lansing Linde there was a gap of approximately nine years between the date of the resolution on which the relevant amending deeds were based and the court hearing. The gap between the date of the resolution and the date of the amending deeds was approximately two years. In the Gallaher case, by contrast, the gap between the court hearing and the date of the initial GMP Policy decision was some 25 years. Within that period there were gaps of seven and nine years respectively between the GMP Policy decision and the execution of the 1987 and 1989 amending deeds. 
In Lansing Linde, Rimer J's view was that the passage of time was such that those giving evidence must necessarily have 'reconstructed' events in their own minds and, therefore, the reliability of their evidence needed to be assessed with care. He did not, however, suggest that the evidence had been fabricated and, in fact, stressed that he believed the witnesses were truthful.

'Everyone's evidence ... about the question of consent and its importance, and the presumption that it was being retained, came out so positively and clearly (rather like name, rank and number, as Mr Green suggested) that a bystander might have been forgiven for thinking that the witnesses had thought of little else in and since 1990. There is, in short, a danger that they may have convinced themselves that they had intentions at the time which they did not: and in the light of the fact that the intentions they now assert are inconsistent, with some of the contemporaneous documentation, I approach Lansing's evidence with caution'. ${ }^{36}$

In Gallaher, similarly, much of the contemporaneous documentation did not expressly support the alleged intention. In these circumstances and in view of the passage of time, Counsel for the representative defendants emphasised the need for the court to view with circumspection witness recollections which did not accord with or which extended beyond the documentary evidence. Unfortunately, this submission is not specifically addressed in Etherton J's judgment and the assumption must be that this factor had little influence on his analysis of the evidence.

Another consequence of the passage of time can be changes in key personnel. This was not really an issue in Linde because of the relatively short time between the date of the resolution and the date of the amending deeds to reflect the resolution. However, in Gallaher, there was a seven-year gap between the GMP Policy decision and the 1987 deed. Very few of those who approved the 1987 deed had had any involvement with the GMP policy decision.

Nonetheless, Etherton J took the view that the evidence demonstrated a continuing policy of the respective boards of directors of the employer and of the trustee company to exclude GMPs from pensions in payment increases and that this was unaffected by the changes in individual directors. It is difficult to see how this approach can be applied where the trustee body is a collection of individual trustees rather than a trustee company.

Additionally, on the subject of passage of time, Gallaher reinforced the position that delay alone is not a defence to a rectification claim. The delay must render it unjust to grant the relief. There was no injustice in Gallaher as pension increases had, in fact, only been paid on the excess pension over GMP and there was apparently no expectation among members for pension increases to apply also to the GMP.

\section{The degree of understanding of the intended amendments}

Rimer J and Etherton J adopted strikingly different approaches to the degree of understanding of the intended amendments that each expected the trustees and employer to have in order to prove intention on the balance of probabilities.

In Lansing Linde, the deeds to be rectified were lengthy, consolidating trust deeds each in excess of 100 pages long and of which the offending wording constituted only an extremely small part. By contrast, the 1987 and 1989 deeds in the Gallaher case were both short, simple deeds dealing, in 
each case, only with the one amendment to pension increases.

It is understandable why the parties in Lansing Linde would not have identified the failure to mention the consent requirement on early retirement in the amending deed. However, it is hard to understand how the parties in Gallaher could have failed to spot that the pension increases were not restricted to the pension in excess of the GMP. Indeed, Etherton $\mathrm{J}$ found that those present at the relevant meetings 'were not consciously thinking about restricting increases to the part of the pension in excess of the GMP'. However, it was sufficient for rectification that their intention was to guarantee the increases that had previously been discretionary and not to change the existing policy even though there was no evidence that there were any documents before the meetings which explained the existing policy.

In Lansing Linde, Rimer J took a much harder line. In his view it was fatal to the claimant's case that the issue of consent was not discussed or considered by the employer and trustees at the appropriate meeting. He refused to accept that the parties did not intend to change the existing consent requirement, as there was no evidence that they had had before them the document that contained the existing consent requirement or that they had that requirement in mind.

\section{Hastings-Bass}

\section{The rule}

A claimant seeking rectification will invariably ask for relief under the principle in Hastings-Bass ${ }^{37}$ as an alternative. This is a useful alternative to rectification as it can apply where rectification cannot be ordered. In particular, the Hastings-Bass principle does not require evidence of the employer's intentions provided that the amendment being attacked was required to be effected by, or required the consent of the trustee.

Broadly, the rule in Hastings-Bass is set out in the following passage of the Court of Appeal's judgment delivered by Lord Buckley:

'where by the terms of a trust ... a trustee is given a discretion as to some matter under which he acts in good faith, the court should not interfere with his action notwithstanding that it does not have the full effect which he intended unless (1) what he has achieved is unauthorised by the power conferred on him, or (2) it is clear that he would not have acted as he did (a) had he not taken into account considerations which he ought to have taken into account or (b) had he not failed to take into account considerations which he ought to have taken into account'.

The rule was subsequently re-stated in a positive form by Warner J. in Mettoy Pension Trustees Ltd $v$ Evans as follows:

'where a trustee acts under a discretion given to him by the terms of the trust, the court will interfere with his action if it is clear that he would not have acted as he did had he not failed to take into account considerations which he ought to have taken into account'. ${ }^{38}$

\section{Uncertainties}

The scope and application of the Hastings-Bass rule have stimulated much academic and professional comment and have led to some divergence of judicial opinion.

Consequently, there are a number of uncertainties surrounding the rule. Some of these were argued before Etherton J in Gallaher, however, his decision to grant rectification made it unnecessary to 
consider the Hastings-Bass rule in any detail. Therefore his comments on these issues are obiter.

Some of these uncertainties are considered briefly below.

\section{Is a breach of fiduciary duty required?}

In Abacus Trust Co (Isle of Man) v Barr ${ }^{39}$ Lightman $\mathrm{J}$ considered the rule in Hastings-Bass at great length. His view was that the trustees' failure to take account of relevant considerations and/or their taking account of irrelevant considerations must amount to a breach of fiduciary duty in order to invoke the rule in Hastings-Bass.

There has been much criticism of this on the particular basis that it appears to have no foundation in either Hasting Bass itself or in Mettoy. However, Lightman J appears to have been approaching this from the perspective that circumstances in which the rule applies will necessarily involve a breach of fiduciary duty:

'the existence of the fiduciary duty on the part of trustees governing the exercise of their fiduciary powers requires trustees to inform themselves of the matters which the are relevant to the decision ... and, in arriving at their decisions whether and how to exercise their discretionary powers to take into account all relevant but no irrelevant factors. The fiduciary duty requires trustees to follow a correct procedure in the decision-making process. ${ }^{40}$

In Gallaher, Etherton J accepted that he was bound by Lightman J's decision unless it was plainly wrong. He did not feel that it was plainly wrong and so does not deal with this issue at any length in his judgment. However, he did make an interesting observation in dealing with the representative defendants' contention that the only breaches were by the solicitors who drafted the deeds of amendment and the
Gallaher pensions team who instructed them. In his view, the trustees could escape responsibility for any breaches of duty by the pensions team '... merely because, for corporate convenience, they were employed by another company within the Gallaher Group'. ${ }^{41}$

Lightman J's requirement for there to be a breach of fiduciary duty was noted in the case of Burrell \& Another v Burrell $\mathcal{E}$ Others $^{42}$ a private trust case which was heard in the month following the Gallaher case. However, there was no need for the court to reach a decision on this issue. In a subsequent $\operatorname{case}^{43}$ Lord Justice Lloyd expressed the view that there is no need for there to be a breach of fiduciary duty in order for the Hastings-Bass rule to apply.

\section{Is the test 'would' or 'might' ?}

Is it necessary to show that the trustees 'would' have acted differently or 'might' have done so had relevant considerations been taken into account or irrelevant considerations ignored?

Most of the authorities to date suggest that the rule will apply where the trustees might have acted differently. However, Hastings-Bass itself uses a 'would' test.

In the Sieff $v$ Hamilton case, Lord Justice Lloyd expressed the view that the correct test is 'would'.

Is the trustees' decision voidable or void? In Abacus, Lightman J decided that, where the Hastings-Bass rule applies, the trustees' decision is voidable and Etherlon $\mathrm{J}$ in Gallaher expressed the view that this was not plainly wrong. This conflicts with Collins J's observation in $A M P$ ' $\ldots$ that the language of the cases strongly suggests that the application of the principle leads to the act being void rather than voidable'. In that case, Collins J had concluded that, absent rectification, he would have held the 
relevant resolution to be void under the Hastings-Bass rule.

This was not an issue that the court needed to consider in the Burrell case nor in the Sieff $v$ Hamilton case. However, in the latter, Lord Justice Lloyd indicated that he was attracted by the view that the decision might be voidable rather than void.

\section{Mistake}

The wide equitable jurisdiction to relieve from the consequences of mistake will allow the court to set aside a document where it is executed under a mistake as to its effect.

The principle has been most recently re-stated by Millet J in Gibbon v Mitchell:

'... wherever there is a voluntary transaction by which one party intends to confer bounty on another, the deed will be set aside if the court is satisfied that the disponer did not intend the transaction to have the effect that it did. It will be set aside for mistake whether the mistake is a mistake of law or of fact, so long as the mistake is as to the effect of the transaction itself and not merely as to its consequences or the advantages to be gained by entering into it. ${ }^{44}$

As the claim for rectification in Gallaher succeeded, it was unnecessary for Etherton $\mathrm{J}$ to consider the alternative claim to set aside the amending deeds for mistake. Nonetheless he did consider this claim and decided that the deeds could have been set aside for mistake as per Gibbon v Mitchell.

Most significantly, Etherton J decided that it is sufficient to invoke the mistake jurisdiction for a party to have been ignorant of the effects of a transaction. It is not necessary to show that a party had a mistaken positive understanding of the effects of the transaction:

'... regardless of that positive intent, it is perfectly clear from the evidence of the witnesses that they were unaware that the effect of the resolutions ... was to confer a right to 2 per cent LPI increases on the entire pension ... that alternative way of formulating GL's mistake is sufficient to invoke the court's equitable jurisdiction to set aside the 1987 deeds. ${ }^{45}$

\section{Conclusion}

As the third major rectification case involving a pension scheme the Gallaher decision appears to demonstrate a shift in the court's attitude towards the rectification. No longer, it seems, is it a remedy to be 'cautiously watched and jealously exercised'. ${ }^{46}$

Indeed, on the basis of Gallaher, rectification can, in theory, be granted based on witness testimony alone, without the need for objective evidence of intention. Furthermore, it may be granted where the intention of the trustees and the employer is general rather than specific and there is little evidence that the parties have directed their minds to the precise detail of the amendment actually made.

\section{Postscript}

This paper was written in September 2005. Since then, there has been a further case on pension scheme rectification - Xchanging Global Insurance Systems Ltd $v$ Clark $^{47}$ in which the High Court granted rectification. The decision in that case does not change any of the views expressed in this paper.

\section{References}

1 Mackenzie v Coulson [1869] LR 8 Eq 368 at 375.

2 AMP v Barker [2000] ALL ER 2208.

3 Walker Property Investments (Brighton) Ltd $v$ Walker [1947] 177 LT 204.

4 Whiteside $v$ Whiteside [1950] Ch 65 (in which the court refused rectification even though it would, by operating retrospectively, have had tax advantages which the voluntary rectification lacked).

5 Nittan (UK) Ltd $v$ Solent Steel Fabrication Ltd [1981] Lloyds Rep.633. 
6 Templiss Properties Ltd v Hymans [1999] EGCS 60.

7 Robert James Walker $v$ Geo. H. Medlicott \& Son (a firm) [1999] 1 All ER 685.

8 Pilkington $v$ Wood [1953] 2 ALL ER 810.

9 AMP $v$ Barker (as above) at 65-67.

10 Breadalbane v Chandos [1837] 2 My \& Cr. 711.

11 Frederick E Rose (London) Ltd v William H Pim Jnr \& Co Ltd [1953] 2 QB 450 (this was a case concerning rectification of a contract: clear evidence of a prior agreement in line with the intention was required).

12 Templiss Properties Ltd v Hymans.

13 Re Butlin's Settlement Trusts [1976] CH 251.

14 Pyke v Peters [1943] KB 242.

15 Lovesy $v$ Smith [1880] 15 Ch D 655.

16 A Roberts \& Co Ltd v Leicestershire County Council [1961] CH 555.

17 Kemp v Neptune Concrete Ltd [1988] 2 EGLR 87. 18 Re Butlin's Settlement Trusts [1976] (see above).

19 Re Butlin's Settlement Trusts (as above).

20 Thomas Bates \& Sons Ltd $v$ Wyndhams (Lingerie) Ltd [1981] 1 WLR 505 at 521.

21 Cambro Contractors Ltd v John Kennelly Sales Ltd; The Times, 14th April, 1994.

22 Earl of Beauchamp $v$ Winn (1873) LR 6 HL 223.

23 Lansing Linde Ltd v Alber [2000] OPLR 1.

24 AMP $v$ Barker (as above).

25 Gallaher Ltd v Gallaher Pensions Ltd [2005] O4 PBLR.
26 Drake Insurance v McDonald [2005] 32 PBLR.

27 Re Hastings-Bass [1975] Ch 25.

28 Gibbon v Mitchell [1991] WLR 1304.

$29 A M P v$ Barker at 66.

30 AMP $v$ Barker at 65.

31 AMP $v$ Barker at 67-68.

32 Dormer $v$ Sherman [1966] 110 Sol Jo 171.

33 McCormack v McCormack [1877] 1LR Ir 119.

34 Westland Savings Bank v Hancock [1987] 2 N2LR 21 and Anfrank Nominees Pty Ltd $v$ Connell [1989] 1ASCR 365.

35 Para 144.

36 Para 145.

37 Re Hastings-Bass [1975] Ch 25.

38 Mettoy Pension Trustees Ltd v Evans [1990] 1WLR 1587.

39 Abacus Trust Co (Isle of Man) v Barr [2004] 59 PBLR.

40 Para 16.

41 Para 179.

42 Burrell and Another v Burell \& Others PLR [2005] 289.

43 The Honourable Sir David Daniel Sieff and Others $v$ David Hamilton Fox and Others [2005] EWHC 1312(ch).

44 Gibbon v Mitchell [1991] WLR 1304.

45 Para 158.

46 Whiteside $v$ Whiteside and others [1950] 1Ch 65.

47 Xchanging Global Insurance Systems v Clark. 